\title{
Asymptomatic bacteriuria among pregnant women attending tertiary care teaching hospital
}

\author{
Harish Babu B.G. ${ }^{1}$, S. Khaja Moinuddin ${ }^{2, *}$, Vinosha ${ }^{3}$, Arpita Deb ${ }^{4}$ \\ ${ }^{\mathbf{1}}$ Assistant Professor, Dept. of Obstetrics and Gynecology, ${ }^{2}$ Research Scholar, Dept. of Microbiology, ${ }^{\mathbf{3}, \mathbf{4}}$ Junior Resident, Dept. of
} Obstetrics, Vinayaka Mission Medical College and Hospital, Karaikal, Puducherry, India

*Corresponding Author:

Email: moinnewlook@gmail.com

\begin{abstract}
Introduction: One of the causes for adverse perinatal outcome is asymptomatic bacteriuria (ASB). The aim of this study is to determine the prevalence of asymptomatic bacteriuria among pregnant women.

Materials and Methods: A total of 205 urine specimens were collected by clean catch method from pregnant women attending Vinayaka Missions Medical College and Hospital, to screen asymptomatic bacteriuria. Collected urine samples were sent to microbiology laboratory and subjected to standard microbiological procedures to identify the pathogen.

Results: Out of 205 midstream urine specimens, 21 samples yielded significant bacterial growth and accounted for $10 \%$ asymptomatic bacteriuria. Asymptomatic bacteriuria was predominantly found between the age group of 18-25 years (52.38\%). Significant bacterial growth was found in the specimens collected during three trimesters. Predominantly growth was seen from the urine specimens collected during second $8(38.10 \%)$ and third trimester $8(38.10 \%)$. Escherichia coli was the predominant bacteria isolated and accounted for $33.33 \%$. Nitrofurantoin was found to be the most effective towards Gram positive and Gram negative bacteria.

Conclusion: In our study, prevalence of asymptomatic bacteriura among pregnant women was $10 \%$. Predominantly isolated bacteria was Escherichia coli. Among commonly used antibiotics to treat urinary tract infections, Nitrofurantoin was found to be the most effective drug.
\end{abstract}

Keywords: Asymptomatic bacteriuria, Escherichia coli, Nitrofurantoin.

\section{Introduction}

One of the most commonly encountered health problems in community and hospital setting is Urinary tract infection (UTI). Urinary tract infections are categorized into two based on symptoms, symptomatic and asymptomatic. Pregnant women are at high risk for UTIs. The altered physiological, anatomical and hormonal changes during Pregnancy makes the antenatal mother more prone to Urinary tract infection. Presence of one lakh or more than one lakh bacteria per $\mathrm{ml}$ of urine specimen collected by clean catch method and without typical symptoms of urinary tract infection (UTI) is pertained as asymptomatic bacteriuria(ASB). ${ }^{1}$ Asymptomatic bacteriuria among pregnant women ranged between 2 to $15 \%$.,3,4 $^{2,3}$

During pregnancy ASB may increase the chances of complications such as, higher incidence of preterm labour, i.e. about $13.3 \%$ as compared to $7.6 \%$ in pregnant women without ASB. More possibilities of preterm amniotic sac rupture, oligohydramnios or polyhydramnios and higher incidence of recurrent pregnancy loss. ${ }^{5}$ Acute pyelonephritis is the most severe complication among pregnant women with ASB which may further leads to urosepsis, higher maternal and foetal morbidity. ${ }^{6}$

The most commonly reported etiologic agent of bacteriuria is Escherichia coli, followed by Proteus mirabilis (P. mirabilis), Klebsiella pneumonia (K. pneumonia) and Pseudomonas aeruginosa ( $\mathrm{P}$. aeruginosa). Gram-positive organisms, including B streptococci, Enterococcus faecalis (E. faecalis) and coagulase-negative staphylococci (CoNS), are less commonly recognised as etiologic agents of bacteriuria. $^{7}$ Detection of asymptomatic bacteriuria in pregnant women has become a part antenatal care and majority of antenatal guidelines contain routine screening for asymptomatic bacteriuria.

The aim of this study was to determine the prevalence of asymptomatic bacteriuria among pregnant women attending our tertiary teaching hospital.

\section{Material and Methods}

This was a prospective, observational study in which a total of 205 urine samples were collected by clean catch method from pregnant women attending Obstetrics and Gynaecology at Vinayaka Mission's Medical College and Hospital, over a period of fourteen months. Before sample collection details from participants such as maternal age, gravidity, parity, age of gestation, along with emphasis on past medical and obstetric history were taken. Informed verbal consent was obtained from all the participants. Urine specimens collected from the participants were sent to the department of microbiology and processed as per standard microbiological methods. The samples were inoculated for semi-quantitative culture on bacteriological culture media. Specimen inoculated plates were kept in incubator at $37^{\circ} \mathrm{C}$ for overnight. If the colony count was $\geq 10^{5}$ was as significant bacteriuria 
and if the colony count is below $10^{5}$ considered as insignificant growth. Further Gram's staining and biochemical reactions were performed. More than one type of colonies on culture plate was considered as contamination and repeat sample was requested. ${ }^{8}$ Disc diffusion technique was used to determine antibiotic susceptibility of isolates. ${ }^{8}$

Exclusion criteria: UTI symptoms (like frequency, urgency or dysuria), Fever, Diabetes mellitus or Gestational diabetes, Renal stones or urinary tract anomalies, Antibiotic intake in preceding 2 weeks.

\section{Results}

A total of 205 urine specimens from pregnant women were screened for asymptomatic bacteriuria.
21(10\%) urine specimens yielded significant bacterial growth. Majority of urine specimens yielded significant bacterial growth were belonged to the age of 18-25 years $(52.38 \%)$ followed by 26-35 years (33.33\%). Bacterial growth was significant in three urine samples collected from the pregnant women belonged to between the age group of 36-40 years (14.28\%).(Table.1)

Significant bacterial growth was found in the specimens collected during three trimesters. Predominantly growth was seen from the urine specimens collected during second $8(38.10 \%)$ and third trimester $8(38.10 \%)$. Least isolation rate was seen in first trimester 5(28.8\%). (Table.1)

Table 1: Age and gestation wise distribution of asymptomatic bacteriuria

\begin{tabular}{|l|c|}
\hline \multicolumn{1}{|c|}{ Age(in years) } & Asymptomatic bacteriuria \\
\hline $18-25$ & $11(52.38 \%)$ \\
\hline $26-35$ & $7(33.33 \%)$ \\
\hline $36-40$ & $3(14.28 \%)$ \\
\hline Gestational age & \\
\hline First trimester & $5(28.8 \%)$ \\
\hline Second trimester & $8(38.10 \%)$ \\
\hline Third trimester & $8(38.10 \%)$ \\
\hline
\end{tabular}

Escherichia coli was the predominant bacteria isolated and accounted for $33.33 \%$ followed by Klebsiella species and Proteus species which accounted for 23.81 and $19.04 \%$ respectively. Stahylococcus saprophyticus was found to be least isolated bacteria which accounted for $4.76 \%$. (Table.2)

Table 2: Bacteria isolated from urine specimens

\begin{tabular}{|l|c|}
\hline \multicolumn{1}{|c|}{ Bacteria } & Number (\%) \\
\hline Escherichia coli & $7(33.33 \%)$ \\
\hline Klebsiella species & $5(23.81 \%)$ \\
\hline Proteus species & $4((19.04 \%)$ \\
\hline Enterococcus & $2(9.52 \%)$ \\
\hline Stahylococcus aureus & $2(9.52 \%)$ \\
\hline Staphylococcus saprophyticus & $1(4.76 \%)$ \\
\hline Total & $21(100 \%)$ \\
\hline
\end{tabular}

Among the antibiotics tested against bacteria isolated from urine samples. All isolated Gram negative bacilli were susceptible to Imipenam and piperacillin/tazobactum (100\%) except klebsiella species and accounted for $80 \%$ susceptibility to piperacillin/tazobactum. Other than imipenam and piperacillin/tazobactum, nitrofurantoin was found to be highly effective toward all Gram negative and Gram positive bacteria. But Proteus species showed 50\% resistance towards nitrofurantoin. Majority of uropathogens were resistance ampicillin. (Table.3)

Table 3: Susceptibility pattern of uropathogens

\begin{tabular}{|l|c|c|c|c|c|c|}
\hline \multicolumn{1}{|c|}{ Bacteria(N=21) } & Ampicillin & Amoxyclav & Nitrofurantoin & Norfloxacin & Imipenam & $\begin{array}{c}\text { Piperacillin/ } \\
\text { Tazobactum }\end{array}$ \\
\hline E.coli(7) & $2(28.57 \%)$ & $4(57.14 \%)$ & $7(100 \%)$ & $3(42.85 \%)$ & $7(100 \%)$ & $7(100 \%)$ \\
\hline Klebsiella species(5) & $1(20 \%)$ & $4(80 \%)$ & $4(80 \%)$ & $2(40 \%)$ & $5(100 \%)$ & $4(80 \%)$ \\
\hline Proteus species(4) & $2(50 \%)$ & $4(100 \%)$ & $2(50 \%)$ & $2(50 \%)$ & $4(100 \%)$ & $4(100 \%)$ \\
\hline Enterococci(2) & $1(50 \%)$ & $2(100 \%)$ & $2(100 \%)$ & $0(0 \%)$ & NT & $2(100 \%)$ \\
\hline S.aureus(2) & $0(0 \%)$ & $2(100 \%)$ & $2(100 \%)$ & $2(100 \%)$ & NT & $2(100 \%)$ \\
\hline S.saprophyticus(1) & $0(0 \%)$ & $1(100 \%)$ & $1(100 \%)$ & $1(100 \%)$ & NT & $1(100 \%)$ \\
\hline
\end{tabular}

NT-Not tested 


\section{Discussion}

In the present study, the prevalence of asymptomatic bacteriuria was found to be $10 \%$. This is in agreement with the studies conducted by Kehinde et al(10.7\%) 9 and Alemu et (10.4\%) 10 According to Turpin et al, 11 the prevalence of asymptomatic bacteriuria was found to be $7.3 \%$ and another study conducted by Gayathree et al showed $6.2 \%$ of asymptomatic bacteriuria among pregnant women. Least prevalence was shown Sheiner et al, ${ }^{12}$ only $2.5 \%$ ASB among pregnant women.

Few studies conducted previously showed high prevalence of asymptomatic bacteriuria among pregnant women. According to the study conducted by by Akerele et al 13 prevalence rate of asymptomatic bacteriuria was $86.6 \%$ among pregnant women. As per Rajarathnam et al, prevalence rate of asymptomatic bacteriuria among pregnant women was $13.2 \% .{ }^{14}$ These varying results may have been due to differences in the areas being studied, in the social habits of the communities being studied and in the socio-economic statuses, standards of personal hygiene and education levels of the patients being studied.

Asymptomatic bacteriuria was predominantly found between the age group of 18-25 years $(52.38 \%)$ followed by $26-35$ years $(33.33 \%)$. As per the study conducted by Shirazi et al ${ }^{15}$ prevalence was $13.8 \%$ in age group less than 21 years compared to $3 \%$ in age group over 30 years. As per Alghalibiet al., ${ }^{16}$ prevalence of ASB was high in pregnant women whose age ranged between 21-25 years of age. But in the study conducted by Turpin et al. ${ }^{11}$ higher prevalence of ASB in pregnant women was ranged between 35-39 years of age. This high incidence of ASB in the young reproductive age group is due to early pregnancy and multiparity in our country, particularly in the rural areas.

In our study, prevalence rate asymptomatic bacteriuria during second and third trimester was $38.10 \%$. Prevalence rate of ASB among urine specimens collected during first trimester showed only $28 \%$. According to the study conducted by Gayathree et $\mathrm{al},{ }^{17}$ asymptomatic bacteriuria was found to be high in IIIrd trimester $(61.77 \%)$ compared to IInd trimester $(32.35 \%)$ and in the Ist trimester $(5.88 \%)$ of pregnancy.

According to the study conducted by Prasanna et al, ${ }^{18}$ majority of the women with ASB were in $3^{\text {rd }}$ trimester (49\%). The incidence of ASB is more pronounced in the third trimester, may be due to the changes related to advancing gestational age. This leads to stasis of urine and encourage bacterial multiplication.

In the present study, Escherichia coli was the predominant bacteria isolated and accounted for $33.33 \%$ followed by Klebsiella species and Proteus species which accounted for 23.81 and $19.04 \%$ respectively. Stahylococcus saprophyticus was found to be least isolated bacteria which accounted for $4.76 \%$.
Senthilnath et $\mathrm{a}^{19}$ and Sujatha et $\mathrm{a}^{20}$ have also showed that Escherichia coli as the commonest isolate. In the present study, Pseudomonas aeruginosa was not isolated whereas other studies showed P.aeruginosa as uropthogen in urine specimens collected from pregnant women. ${ }^{21}$

Antimicrobial susceptibility of uropathogens vary from region to region and even from hospital to hospital due to the emergence of resistant strains caused by the indiscriminate use of antibiotics. In our study majority of bacteria were resistant commonly used antibiotic ampicillin. Resistance to ampicillin was exhibited by majority of strains of E. coli in European countries and Canada averaged $29.8 \%$, but was as high as $53.9 \%$ in Spain. ${ }^{22}$ In our study nitrofurantoin was found to be the most effective antibiotic among commonly used antimicrobials against uropathogens. According to NCCLS data from 2000 , only $1 \%$ resistance rate was observed towards nitrofurantoin among uropathogens. ${ }^{23}$ But certain limitations restricts the usage of nitrourantoin .Efficacy of nitrofurantoin was found to be poor towards Proteus species. It may cause haemolytic anaemia in patients who have glucose-6phosphate dehydrogenase deficiency. ${ }^{24}$

\section{Conclusion}

In our study, prevalence of asymptomatic bacteriura among pregnant women was $10 \%$. Escherichia coli was the predominant pathogen isolated. Nitrofurantoin was found to be the most effective drug among commonly used antibiotics to treat urinary tract infections.

\section{References}

1. National Collaborating Centre for Women's and Children's Health. Antenatal care: routine care for the healthy pregnant woman. London: RCOG Press; 2008. https://www.nice.org.uk/guidance/cg62/evidence/fullguidelinecorrected- june-2008-196748317. Accessed 22 Feb 2016.

2. Lorentzon S, Hovelius B, Miörner H, Tendler M, Aberg A. The diagnosis of bacteriuria during pregnancy. Scand J Prim Health Care. 1990;8(2):81-3.

3. Mignini L, Carroli G, Abalos E, Widmer M, Amigot S, Nardin JM, et al. Accuracy of diagnostic tests to detect asymptomatic bacteriuria during pregnancy. Obstet Gynecol. 2009;113(2 Pt 1):346-52.

4. Plauché WC, Janney FA, Curole DN. Screening for asymptomatic bacteriuria in pregnant patients: three office screening systems versus quantitative culture. South Med J. 1981;74(10):1227-9.

5. Teodor Markov Garnizov Asymptomatic bacteriuria in pregnancy from the perspective of public health and maternal health care: review and case report, Biotechnology \& Biotechnological Equipment.2016; 30:3, 443-7, DOI: 10.1080/13102818.2015.1114429

6. Marahatta R, Acharya Dhungel B, Pradhan P, et al. Asymptomatic bacteriurea among pregnant women visitingNepal Medical College Teaching Hospital, Kathmandu, Nepal. Nepal Med Coll J. 2011;13(2):10710 . 
7. Ugbogu O, Ogbonnaya R, Nworie O. Asymptomatic bacteriuria among pregnant women in ABA ABIA state, Nigeria. Niger J Microb 2010; 24: 2024-7.

8. Forbes BA, Sahm DF, Weissfeld AS. Chapter 13, Overview of bacterial identification methods and strategies. Bailey and Scott's diagnostic Microbiology, 12th ed. St.Louis: Mosby; 2007. p. 216-47.

9. Kehinde AO, Adedapo KS, Aimaikhu CO, et al. Significant bacteriuria among asymptomatic antenatal clinic attendees in Ibadan, Nigeria. Trop Med Health. 2011;39 (3):73-6.

10. Alemu A, Moges F, Shiferaw Y, et al. Bacterial profile and drug susceptibility pattern of urinary tract infection in pregnant women at University of Gondar Teaching Hospital, Northwest Ethiopia. BMC Res Notes [Internet]. 2012 [cited 2015 Oct 6];25(5):197. Available from: http://www.biomedcentral.com/17560500/5/197

11. Turpin CA, Minkah B, Danso KA, Frimpong EH. Asymptomatic bacteriuria in pregnant women attending antenatal clinic at Komfo Anokye Teaching Hospital, Kumasi. Ghana Med J 2007;41:26-9.

12. Sheiner E, Mazor DE, Levy A. Asymptomatic bacteriuria during pregnancy. J Maternfetal Neonatal Med. 2009;22:423-7.

13. Akerele J, Abhulimen P,Okonofua F.Prevalence of asymptomatic bacteriuria among pregnant women in Benin city,Nigeria.J obstet

Gynaecol.2001Ma;r21(2):141-4.

14. Rajaratnam A, Baby NM, Kuruvilla IS, et al. Diagnosis of asymptomatic bacteriuria and assiciated risk factors among pregnant women in Mangalore, Karnataka, India. J Clin Dign Res. 2014;8(9):23-5.

15. Shirazi MH, Sadegifard N, Ranjbar, Daneshyar E, Ghasemi A.Incidence of asymptomatic bacteriuria during pregnancy. Pak J Biol Sci.2006;9(1):151-4.

16. Alghalibi SM, Al-Jaufy A, Al-Moayad E. Bacterial urinary tract infection among pregnant women in Sana'a City-Yemen. Arab Gulf J Sci Res 2007;25:2331 .

17. Gayathree L, shetty S, deshpande S R, venkatesha D T. screening for asymptomatic bacteriuria in pregnancy: an evaluation of various screening tests at the hassan district hospital, INDIA. Journal of Clinical and Diagnostic Research [serial online] 2010 August [cited: 2010 August 15 ];4:2702-6.

18. B. Prasanna, M. Naimisha, K.Swathi, Mahaboob V Shaik. Prevalence of Asymptomatic Bacteriuria in Pregnant Women, Isolates and their Culture Sensitivity Pattern. Int.J.Curr.Microbiol.App.Sci .2015;4(8): 2835.

19. Senthilnath TJ, Rajalaksmi PC, Keerthana R, Vigneshwari RS, Revathi RS, Prabhu N et al. Prevalence of asymptomatic bacteriuria among antenatal women in rural tertiary care hospital, Tamilnadu, India. Int J Curr Microbiol App Sci.2013;2(1):80-5.

20. Sujatha, Nawani M. Prevalence of asymptomatic bacteriuria and its antibacterial susceptibility pattern among pregnant women attending the antenatal clinic at Kanpur, India. J Clin Diag Res. 2014;8(4):1-3.

21. Imade PE, Izekor PE, Eghafona NO, Enabulele OI, Ophori E. Asymptomatic bacteriuria among pregnant women. North Am J Med Sci 2010;2:263-6.

22. Kahlmeter G. An international survey of the antimicrobial susceptibility of pathogens from uncomplicated urinary tract infections: the ECO.SENS Project. J Antimicrob Chemother 2003;51:69-76.
23. Sahm DF, Thornsberry C, Mayfield DC, Jones ME, Karlowsky JA. Multidrug-resistant urinary tract isolates of Escherichia coli: prevalence and patient demographics in the United States in 2000. Antimicrob Agents Chemother 2001;45:1402-6.

24. Christensen B. Which antibiotics are appropriate for treating bacteriuria in pregnancy? $J$ Antimicrob Chemother 2000;46 (Suppl. A):29-34. 